\title{
Characteristics of nanostructure dye-sensitized solar cells using food dyes
}

\author{
M. HOSSEINNEZHAD ${ }^{* 1}$ and S. ROUHANI ${ }^{1,2}$ \\ ${ }^{1}$ Department of Organic Colorants, Institute for Colour Science and Technology, \\ Tehran, P.O. Box 16656118481, Tehran, Iran \\ ${ }^{2}$ Centre of Excellence for Colour Science and Technology, Institute for Colour Science and Technology, \\ P.O. Box 16656118481, Tehran, Iran
}

\begin{abstract}
Dye-sensitized solar cells (DSSCs) were prepared using various food dyes. Food dyes are economically superior to organometallic dyes since they are nontoxic and inexpensive. The spectrophotometric evaluation of chosen food dyes in solution and on a $\mathrm{TiO}_{2}$ substrate show that the dyes form J-aggregation on the photoelectrode substrate. Oxidation of potential measurements for used food dyes ensured an energetically permissible and thermodynamically favorable charge transfer throughout the continuous cycle of a photo-electric conversion. The performance of dye-sensitized solar cells based on food dyes was studied. The results illustrate that the dye containing carboxylic acid and sulfonic acid as the acceptor group gave the maximum conversion efficiency $4.20 \%$.
\end{abstract}

Keywords: dye sensitized solar cell; conversion efficiency; food dyes; optical absorption.

\section{Introduction}

One of the greatest challenges in the last decade has been discovering new energy sources with minimum toxicity [1]. The sun is the most affluent source of clean and renewable energy on Earth [2]. According to the pioneering work by Gratzel [3] dye sensitized solar cells (DSSCs) have been proposed as a device to convert solar energy into electrical energy. DSSCs are an inexpensive and environmental photovoltaic technology compared to silicon solar cells [4]. Extensive research has been done for the improvement of the power conversion efficiency [5]. Photosensitizers (ruthenium dyes, free metal organic dyes and natural dyes) are one of the key materials in DSSCs that directly affect conversion efficiency [6]. Several types of organic dyes such as indoline dyes, coumarin dyes, polyene dyes, hemicyanine dyes and thiophene based dyes have been designed for DSSCs devices [7,8]. Azo dyes have been widely studied due to their application in dyeing textile and plastics [9]. In the past few years, significant efforts have been devoted to the use of azo dyes as sensors [10]. Azo dyes combine their optical and electronic properties with good chemical stability and solution process ability [4], which can be used in DSSCs. There are few reports on the application of azo dyes as photosensitizers on DSSCs. Mikroyannidis et al. investigated the application of three new azo dyes in DSSCs. The results show that the overall power conversion efficiency (PCE) of the DSSCs are $2.59 \%-4.17 \%$ for a synthesized azo dye [11]. Mahmood et al. designed a series of azo dyes for DSSCs. All azo dyes showed absorbance in visible

\footnotetext{
*e-mail: hosseinnezhad-mo@icrc.ac.ir
}

region and light harvesting efficiency. These dyes also presented large Voc (1.037-1.128 eV) [4]. There are several reports on the azo food dye application in new technologies as sensor design [12-14]; nevertheless, there aren't studies or reports on the application of food azo dyes in DSSCs.

In this study, for the first time we selected a series of food azo dyes with different substituents and investigated the performance of DSSCs in the absence and presence of the anti-aggregation agent. The spectrophotometric properties of these dyes in solution and on $\mathrm{TiO}_{2}$ substrate and the electrochemical measurements were investigated. Finally, we fabricated DSSCs using food azo dyes as photosensitizers and presented photovoltaic properties. The structures of the azo dye molecules are given in Fig. 1.

\section{Experimental}

\subsection{Materials and instrumentation}

All compounds used in this study were of analytical grade unless otherwise stated. The food azo dyes were obtained from the Institute of Standard and Industrial Research of Iran. Photoelectrodes were fabricated using $\mathrm{TiO}_{2}$ paste from Sharif solar. UV-visible spectrophotometry and fluorimetry were carried out on a Cecil 9200 double beam transmission spectrophotometer and Ocean Optics Usb2000flg fluorometer, respectively.

\subsection{Electrochemical measurements}

Electrochemical measurements of the food azo dyes were carried out in solution of acetonitrile. The oxidation poten- 
<smiles>O=C(O)c1nn(-c2ccc(S(=O)(=O)O)cc2)c(O)c1/N=N/c1ccc(S(=O)(=O)O)cc1</smiles>

Dye 1<smiles>COc1cc(S(=O)(=O)O)c(C)cc1/N=N/c1c(O)ccc2ccccc12</smiles>

Dye 2<smiles>O=S(=O)(O)c1ccc(N=Nc2cc(S(=O)(=O)O)c3ccccc3c2O)c2ccccc12</smiles>

Dye 3<smiles>O=S(=O)(O)c1cc(S(=O)(=O)O)c2c(N=Nc3cccc4c(S(=O)(=O)O)cccc34)c(O)ccc2c1</smiles><smiles>O=S(=O)(O)c1ccc(/N=N/c2c(O)ccc3cc(S(=O)(=O)O)ccc23)cc1</smiles>

Dye 5

Fig. 1. Chemical Structure of food azo dyes.

tial $\left(\mathrm{E}_{\mathrm{ox}}\right)$ was measured using three small-sized electrodes. Ag quasi reference electrode (QRE) was used as the reference. Platinum wires were used as working and counter electrodes. All electrode potentials were calibrated with respect to ferrocene $(\mathrm{Fc}) /$ ferrocenium $\left(\mathrm{Fc}^{+}\right)$redox couplet. An acetonitrile solution of each dye containing tetrabutylammonium perchlorate $\left(0.1 \mathrm{~mol} \mathrm{dm}^{-3}\right)$ and ferrocene (ca. $1 \mathrm{mmol} \mathrm{dm}^{-3}$ ) was prepared. The electrochemical measurements were performed at a scan rate of $100 \mathrm{mV} \mathrm{s}^{-1}$ [15].

\subsection{Dye-sensitized solar cells assembly and photovoltaic characteristics}

A nanocrystalline anatase $\mathrm{TiO}_{2}$ film was coated on a transparent glass support. Each individual food azo dye was adsorbed by dipping a separate coated glass in a $5 \times 10^{-5} \mathrm{M}$ solution containing each dye for 12 hours. The visible bands in the absorption spectrum of the dyes after adsorption on nano $\mathrm{TiO}_{2}$ film only appeared after the $\mathrm{TiO}_{2}$ electrodes were dipped in the dye solution for at least 12 hours. Finally, the film was washed with a 1:1 acetonitrile:ethanolmixed solution. Acenonitrile-ethylenecarbonate $(\mathrm{v} / \mathrm{v}=1: 4)$ containing

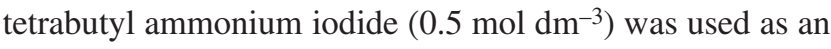
electrolyte. Each dye-adsorbed $\mathrm{TiO}_{2}$ electrode, together with a $\mathrm{Pt}$ counter electrode and the mentioned electrolyte solution was separately assembled into a sealed sandwich type solar cell $[16,17]$. For each solar cell, an action spectrum was measured under monochromatic light with a constant photon number $\left(5 \times 10^{15}\right.$ photon $\left.\mathrm{cm}^{-2} \mathrm{~s}^{-1}\right)$. Photocurrent-photovoltage $(\mathrm{J}-\mathrm{V})$ characteristics were measured under illumination with AM 1.5 simulated sun light $(100 \mathrm{~mW}$ $\left.\mathrm{cm}^{-2}\right)$ through a shading mast $(5.0 \mathrm{~mm} \times 4 \mathrm{~mm})$ by using a Bunko-Keiki CEP-2000 system.

\section{Results and discussion}

A series of monoazo acid dyes with a general structure of Fig. 1, containing sulphonic acid were chosen. The acid food azo dyes had yellow, orange and red hue (Table 1). Azo dyes contain one azo group (monoazo), two azo groups (disazo), three azo groups (thrisazo), or more but do not exist naturally. Azo dyes account for approximately $60-70 \%$ of all synthesized dyes utilized in food industry [18]. On the other hand, azo dyes have applications such as reversible optical storage media, optical switches, electro-optic modulators and chemical sensors [11]. Recently, more attention has been directed to the application of azo dyes in photovoltaic devices because not only they do not cost much but also they have relatively facile dye synthesis and chemical stability [11,19].

Table 1. Acid food azo dyes.

\begin{tabular}{ccc}
\hline Dye & Name & $\begin{array}{c}\text { Observed } \\
\text { Colour }\end{array}$ \\
\hline 1 & Food Yellow 4, Tartrazine & Yellow \\
2 & Food Red 17, Allura Red AC & Red \\
3 & Food Red 3, Azorubine & Red \\
4 & Food Red 7, Ponceau 4R & Red \\
5 & Orange Yellow S, Sunset Yellow FCF & Orange \\
\hline
\end{tabular}

Table 2 shows the wavelength of maximum absorption $\left(\lambda_{\text {max }}\right)$ together with dimethylformamide (DMF) solution for each individual dye, as well as the corresponding $\lambda_{\max }$ on nano $\mathrm{TiO}_{2}$ films in the presence and absence of anti-aggregation agent. Figure 2 illustrates the adsorption curves of one selected dye (Dye 4) in solution, on $\mathrm{TiO}_{2}$ substrate in the absence of anti-aggregation agent and on $\mathrm{TiO}_{2}$ substrate in the presence of anti-aggregation agent. Table 2 
and Figures 1 and 2 show that electron donating or electron withdrawing groups positions on the synthesized dyes not only shift $\lambda_{\max }$ in a DMF solution but also on nano $\mathrm{TiO}_{2}$ to longer wavelengths (i.e., bathochromic shifts for synthesized dyes). However, the same dyes show bathochromic shifts on nano $\mathrm{TiO}_{2}$ compared to their corresponding $\lambda_{\max }$ in DMF solution due to the formation of a partial J-type aggregation on nano $\mathrm{TiO}_{2}$.

Table 2. Absorption properties of azo dyes.

\begin{tabular}{ccccc}
\hline Dye & $\lambda_{\max }(\mathrm{nm})^{\mathrm{a}}$ & $\lambda_{\max }(\mathrm{nm})^{\mathrm{b}}$ & $\lambda_{\max }(\mathrm{nm})^{\mathrm{c}}$ & $\lambda_{\mathrm{F}}(\mathrm{nm})^{\mathrm{d}}$ \\
\hline 1 & 425 & 433 & 432 & 520 \\
2 & 496 & 516 & 504 & 595 \\
3 & 533 & 551 & 541 & 631 \\
4 & 555 & 572 & 560 & 651 \\
5 & 480 & 502 & 490 & 590 \\
\hline
\end{tabular}

a) $\mathrm{DMF}$ solution, b) on $\mathrm{TiO}_{2}$ substrate in the absence of anti-aggregation agent, c) on $\mathrm{TiO}_{2}$ substrate in the presence of anti-aggregation and d) fluorescence emission maxima.

Amongst these food azo dyes, Dye 4 shows maximum bathochromic shifts in DMF solution and nano $\mathrm{TiO}_{2}$ in comparison to the other azo dyes. This can be attributed to an intramolecular charge transfer between the donor and acceptor groups $[7,20]$ which provides an efficient charge separation for the exited state. This is assigned toelectron donating substituents on the electron donor group which, in turn, lowers the level of the lower unoccupied molecular orbital (LUMO), thus reducing the gap between the higher unoccupied molecular orbital (HOMO) and the corresponding LUMO states [21]. The colour of the acid dyes is attributed to azo-hydrazone tautomerism, since the two tautomeric forms generally will have different spectroscopic properties. It is found that the hydrazine forms are always absorbed at longer wavelengths than their azo tautomers. These two forms are presented in Fig. 3. As mentioned above, the dyes can occur in two different hydrazine forms, with the azo system (amino-iminol tautomerism) in Fig. 3. The intra molecular hydrogen bond leads to the rise of a greater charged excited state due to the electrostatic interaction between adjacent groups. This interaction presents a red shift in the UV-Vis spectrum [22]. The fluorescent characteristics of dyes measured in DMF are also reported in Table 2. In DMF solutions, all azo dyes show intense orange fluorescence due to charge transfer to the electron

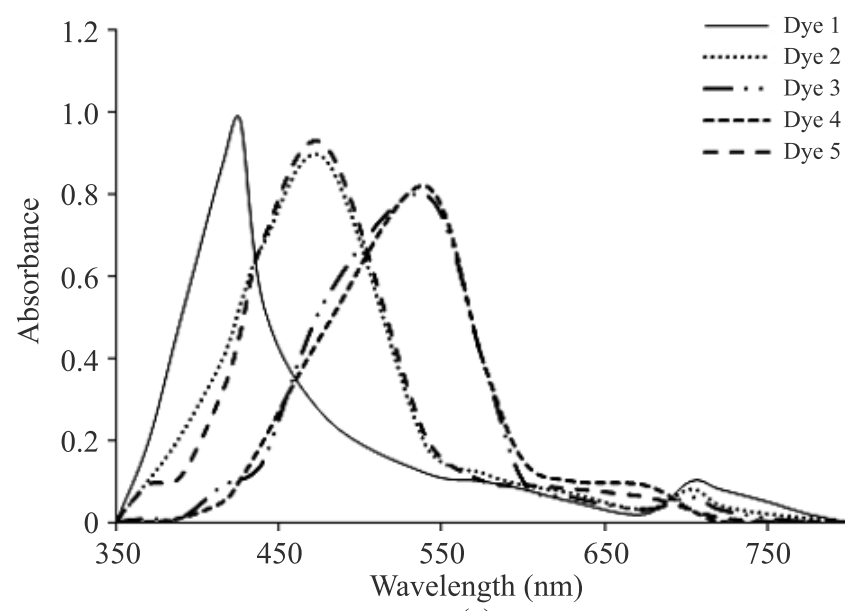

(a)

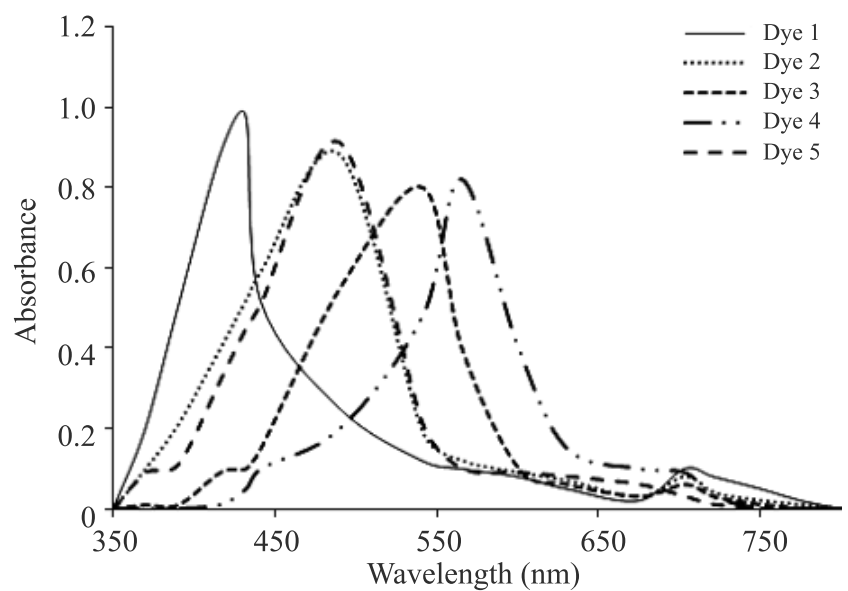

(b)

Fig. 2. UV-Vis absorption spectra of a) in DMF solution and b) on $\mathrm{TiO}_{2}$ in the presence of anti-aggregation agent.

accepting groups. The fluorescence emission maxima $\left(\lambda_{F}\right)$ of the azo dyes in DMF were 540, 595, 631, 651 and 590, respectively.

The oxidation potential $\left(\mathrm{E}_{\mathrm{ox}}\right)$ of all azo dyes were measured in acetonitrile by cyclic voltammetry. Two distinct redox waves were observed in the voltammogram [15]. The first oxidative wave was due to the oxidation of the external standard of Ferrocene and the second wave resulted from the electrochemical oxidation of each dye. The oxidation peak potential $\left(\mathrm{E}_{\mathrm{pa}}\right)$ for Dye 1-Dye 5 can, therefore, be calculated to be $+1.02 \mathrm{~V},+1.08 \mathrm{~V},+0.94 \mathrm{~V},+1.11 \mathrm{~V}$ and

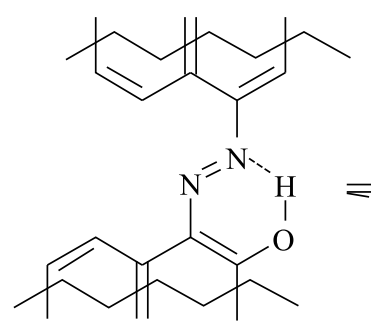

Azo form

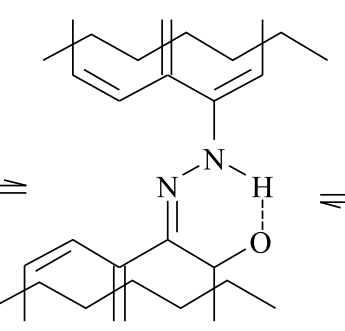

Hydrazone form

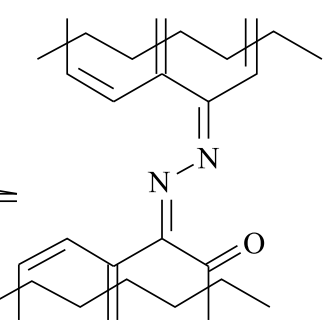

Amino-imidol form

Fig. 3. Azo-hydrazone acid dyes. 
$+1.15 \mathrm{~V}$ vs. $\mathrm{Fc} / \mathrm{Fc}^{+}$(as an external standard Ferrocene/Ferrocenium redox couple) in acetonitrile, respectively. Moreover, fluorescence spectra in solution were calculated. This is considered to correspond to the reduction potential [21]. Then, the $\mathrm{E}_{\mathrm{Ox}}-\mathrm{E}_{0-0}$ level of Dye 1-Dye is calculated to be $-1.13 \mathrm{~V},-1.13 \mathrm{~V},-1.25 \mathrm{~V},-1.06 \mathrm{~V}$ and $-0.99 \mathrm{~V}$, respectively $v s . \mathrm{Fc} / \mathrm{Fc}^{+}$in acetonitrile.

The excited state oxidation potentials (LUMO) of all dyes are more negative than the conduction band gap edge of $\mathrm{TiO}_{2}[-0.5 \mathrm{~V}$ (vs. NHE)]. Provided that an energy gap (between the dye LUMO state and the conduction band of $\mathrm{TiO}_{2}$ ) of $0.2 \mathrm{eV}$ is necessary for efficient electron injection [23], the driving force is sufficient for efficient charge injection. Thus, the electron injection process from each excited dye molecule to the $\mathrm{TiO}_{2}$ conduction band and the subsequent dye regeneration are energetically permissible. The energy levels of the ground state (HOMO) of all azo dyes are sufficiently more positive than the $\mathrm{I}_{3}{ }^{-} / \mathrm{I}^{-}$redox potential $[(0.42 \mathrm{~V}(v s . \mathrm{NHE})][24,25]$, indicating that the oxidized dye formed after electron injection into the conduction band of $\mathrm{TiO}_{2}$ could accept electrons from $\mathrm{I}^{-}$ions in the electrolyte, thus making it thermodynamically favourable. Such electronic structures thus ensure a favourable exothermic flow of charge throughout the photo-electric conversion. Electrochemical properties and band gap of azo dyes are listed in Table 3.

Table 3. Electrochemical properties and band gap of azo dyes.

\begin{tabular}{ccccc}
\hline Dye & HOMO & LUMO & $\mathrm{E}_{0-0}(\mathrm{~V})^{\mathrm{a}}$ & $\mathrm{E}_{\text {gap }}(\mathrm{V})^{\mathrm{b}}$ \\
\hline 1 & 1.02 & -1.13 & 2.15 & 0.63 \\
2 & 1.08 & -1.13 & 2.21 & 0.63 \\
3 & 0.94 & -1.25 & 2.19 & 0.75 \\
4 & 1.11 & -1.06 & 2.17 & 0.46 \\
5 & 1.15 & -0.99 & 2.14 & 0.49 \\
\hline
\end{tabular}

a) Voltage of intersection point between absorption and emission spectra.

b) $\mathrm{E}_{\mathrm{gap}}=\mathrm{E}_{\mathrm{cbTiO}_{2}}-\mathrm{E}_{\mathrm{LUMO}}=-0.5-\mathrm{E}_{\mathrm{LUMO}}$.

Dye-sensitized solar cells (DSSCs) were constructed and compared in order to clarify the relationships between

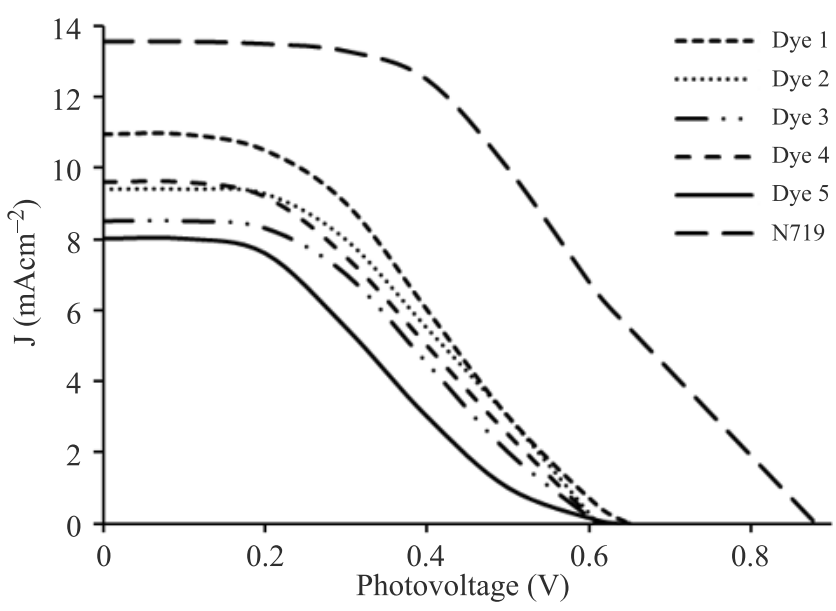

Fig. 4. Current density-voltage characteristics for azo dyes. the sensitizing behaviour of azo dye molecules and their structures. The DSSCs used these dyes as sensitizers for nanocrystalline anatase $\mathrm{TiO}_{2}$. Figure 4 depicts a typical photocurrent-photovoltage ( $\mathrm{J}-\mathrm{V}$ ) curve for cells Dyes 1, Dye 5 and Di-tetrabutylammoniumcis-bis (isothiocyanato) bis(2,2'-bipyridyl-4,4'-dicarboxylato) ruthenium (II) (N719). The detailed photovoltaic parameters are also summarized in Table 4. The solar energy to electricity conversion efficiency $(\eta)$ of the DSSCs is calculated from the short circuit current $\left(\mathrm{J}_{\mathrm{sc}}\right)$, the open-circuit photovoltage $\left(\mathrm{V}_{\mathrm{oc}}\right)$, the fill factor $(\mathrm{FF})$, and the intensity of the incident light $\left(\mathrm{P}_{\mathrm{in}}\right)$ $\left[\mathrm{P}_{\mathrm{in}}=1 \mathrm{mVcm}^{-2}\right]$ as photovoltaic properties $[24,26]$.

Table 4. Photovoltaic performance of DSSCs ${ }^{\mathrm{a}}$.

\begin{tabular}{ccccc}
\hline Dye & $\mathrm{V}_{\mathrm{oc}}(\mathrm{V})$ & $\mathrm{J}_{\mathrm{sc}}\left(\mathrm{mAcm}^{-2}\right)$ & $\mathrm{FF}$ & $\eta(\%)$ \\
\hline 1 & 0.68 & 10.95 & 0.56 & 4.20 \\
2 & 0.62 & 9.43 & 0.53 & 3.10 \\
3 & 0.61 & 8.50 & 0.54 & 2.80 \\
4 & 0.64 & 9.61 & 0.53 & 3.32 \\
5 & 0.61 & 8.01 & 0.53 & 2.48 \\
$\mathrm{~N} 719$ & 0.88 & 13.57 & 0.71 & 8.47 \\
\hline
\end{tabular}

a) with anti-aggregation agent in dye solution and containing tetrabutyl ammonium iodide $\left(0.5 \mathrm{~mol} \mathrm{dm}^{-3}\right)$ as electrolyte

The results were obtained under full sunlight (AM 1.5 solar condition), and as shown in Table 4, demonstrate that a maximum value of $4.20 \%$ for the conversion efficiency of cells containing Dye 1 was achieved in the presence of anti-aggregation agent. The larger conversion efficiency of Dye 1 photosensitizer is probably due to the presence of four suitable anchoring groups of the respective substituted azo dyes and/or presence of anti-aggregation agent. Reduced aggregation of dye molecules is directly related with faster electron transfer from the excited state of the dye molecules to the $\mathrm{TiO}_{2}$ conduction band in DSSCs. Therefore, anchoring dye molecules highly is critical for absolute adsorption of sunlight in DSSCs thus, conversion efficiency directly relies on a suitable dye deposition $[27,28]$. The conversion efficiency of solar cells containing azo dyes is usually higher than $2 \%$. For example three organic dyes with various substituents as the electron donors and carboylic acid as the electron acceptor were prepared by Mikroyannidis et al. [11]. These organic dyes were then utilized as photosensitizers in DSSCs with conversion efficiencies of $4.17 \%, 3.26 \%$ and $2.59 \%$, respectively. Furthermore, four organic azo dyes with carboxylic acid as the acceptor group were prepared by Mahmood et al. [4]. The PCE of the DSSCs based on such synthesized dyes ranged from $3.56 \%$ to $3.64 \%$. Thus, performance of DSSCs containing Dye 1-Dye 5 is better than solar cells based on other azo dyes which is probably due to more facility for the motion of electrons in such dye structures. The organic dyes with two or more anchoring groups show the highest lifetime of the first excited state, implying the potentially good ability in electron injection from dye molecules to $\mathrm{TiO}_{2}$ substrate [28]. Therefore, Dye 4 with three sulphonic acids has higher 
conversion efficiency than Dyes 2, 3 and 5. The larger power conversion efficiency of Dye 2 is attributed to the presence of methoxy and methyl group as activating substituents on dye molecules. Nonetheless, the DSSCs with N719 show a better performance than the DSSCs based on Dye 1 to Dye 5. This is due to the molecular structure of N719 dye, which leads to the Metal Ligand Charge Transfer (MLCT) effect [29] that reduces the charge recombination at the dye molecules and phtoelectrode interface, hence providing a higher $\mathrm{V}_{\mathrm{oc}}$ value. On the other hand, the N719 dye standard contains the expensive ruthenium metal which economically limits its general use.

\section{Conclusions}

Five metal free organic dyes to be used as photosensitizers in DSSCs were selected based on food azo dyes by employing a simple naphthyl residue as a part of đ-conjugation system and simple carboxylic acid and/or sulfonic acid as the electron acceptor anchoring groups. The spectrophotometric properties of the food azo dyes in solvent and on $\mathrm{TiO}_{2}$ films in the absence and presence of the anti-aggregation agent were examined. According to the results, the absorption maxima of food azo dyes separately applied on $\mathrm{TiO}_{2}$ films gave bathochromic shifts compared to the corresponding dye spectra in the solutions. This bathochromic shifts is due to the form J-aggregateon the photoelectrode substrate, but the amounts of aggregation decreased in the presence of anti-aggregation agent because of the reduction in bathochromic shifts. Moreover, the electron transfer process is reduced duo to the aggregation of molecular dyes; DSSCs, therefore, were prepared in the presence of the anti-aggregation agent. Finally, the food azo dyes were utilized in DSSCs and their photovoltaic behaviours were investigated. A solar energy to electricity conversion efficiency of $4.20 \%$, $2.80 \%, 3.10 \%, 3.32 \%$ and $2.48 \%$ were achieved for Dye $1-$ Dye 5 , respectively. Dye 1 , containing $\mathrm{COOH}$, gave higher conversion efficiency than other food azo dyes which is attributable to the stronger electron withdrawing ability of Dye 1.

\section{Acknowledgement}

The authors sincerely thank the Centre of Excellence for Colour Science and Technology for making this investigation possible.

\section{References}

1. M. Hosseinnezhad, S. Moradian, and K. Gharanjig, "Synthesis and application of two organic dyes for dye-sensitized solar cells", Prog. Colour Colorants Coat. 6, 109-117 (2013).

2. J. Etula, "Comparison of three Finnish berries as sensitizers in a dye-sensitized solar cell", Eur. J. Young Sci. Eng. 1, 77-84 (2012).

3. B. O'Regan and M. Gratzel, "A low cost, high efficiency solar cell based on dye-sensitized colloidal $\mathrm{TiO}_{2}$ films", Nature 353, 737-740 (1991).
4. A. Mahmood, M. Hussain Tahir, A. Irfan, A.G. Al-Sehemi, and M.S. Al-Assiri, "Heterocyclic azo dyes for dye sensitized solar cells: A quantum chemical study", Comput. Theor. Chem. 1066, 94-99 (2015).

5. N.T.R.N. Kumara, P. Ekanayake, A. Lim, L.Y.C. Liew, M. Iskandar, L.C. Ming, and G.K.R. Senadeera, "Layered co-sensitization for enhancement of conversion efficiency of natural dye sensitized solar cells", J. Alloy Compd. 581, 186-191 (2013).

6. M. Berginc, U. Opara-Krasorec, and M. Hocevar, "Performance of dye-sensitized solar cells based on Ionic liquids: Effect of temperature and iodine concentration", Thin Solid Film. 516, 7155-7159 (2008).

7. M. Gratzel, "Dye-sensitized solar cells", J. Photochem. Photobiol. C: Photochem. Rev. 4, 145-153 (2003).

8. M. Hosseinnezhad, S. Moradian, and K. Gharanjig, "Investigation of effect of anti-aggregation agent on the performance of nanostructure dye-sensitized solar cells", Opto-electron. Rev. 23, 126-130 (2015).

9. M. Hosseinnezhad, S. Moradian, and K. Gharanjig,"Novel organic dyes based on thioindigo for dye-sensitized solar cells", Dye Pigment. 123, 147-153 (2015).

10. S. Rouhani and T. Haji-ghasemi, "Novel potentiometric sensors for the determination of cochineal red a and its application to food analysis", Anal. Bioanal. Electrochem. 1, 49-59 (2009).

11. J.A. Mikroyannidis, D.V. Tsagkournos, P. Balraju, and G.D. Sharma, "Low band gap dyes based on 2-styryl-5-phenylazo-pyrrole: Synthesis and application for efficient dye-sensitized solar cells", J. Power Sources. 196, 4152-4161 (2011).

12. M.L.G. Vieria, V.M. Esquerdo, L.R. Nobre, G.L. Dotto, and L.A.A. Pinto, "Glass beads coated with chitosan for the food azo dyes adsorption in a fixed bed column", J. Ind. Eng. Chem. 20, 3387-3393 (2014).

13. S. Rouhani and S. Haghgoo, "A novel fluorescence nanosensor based on 1,8-naphthalimide thiophene doped silica nanoparticles, and its application to the determination of methamphetamine", Sens. Actu. B. Chem. 209, 957-965 (2014).

14. S. Rouhani, "A novel electrochemical sensor for sunset yellow based on a platinum wire coated electrode", Anal. Lett. 42, 141-153 (2009).

15. M. Hosseinnezhad and S. Rouhani, "Application of azo dye as sensitizer in dye-sensitized solar cells", Prog. Color Colorants Coat. 8, 259-265 (2015).

16. M. Matsui, T. Fujita, Y. Kubota, and K. Funabiki, "The use of indoline dyes in a zinc oxide dye-sensitized solar cell", Dyes Pigment. 80, 233-238 (2009).

17. $\mathrm{Y}$. Wu and $\mathrm{W}$. Zhu, "Organic sensitizers from $\mathrm{D}-\pi-\mathrm{A}$ to $\mathrm{D}-\mathrm{A}-\pi-\mathrm{A}$ : effect of the internal electron-withdrawing units on molecular absorption, energy levels and photovoltaic performances", Chem. Soc. Rev. 42, 2039-2058 (2013).

18. Y. Gao, C. Li, J. Shen, H. Yin, X. An, and H. Jin, "Effect of food azo dye tartrazine on learning and memory functions in mice and rats and the possible mechanisms involved", $J$. Food Sci., 76, T125-T129 (2011).

19. A. Vig, K. Sirbiladze, H.J. Nagy, P. Aranyosi, I. Rusznk, and P. Sallay, "Polymethine dyes derived from 2,2-difluoro-3,1, 2- $(2 \mathrm{H})$-oxaoxoniaboratines with polymethylene bridge groups in the chromophore", Dyes Pigment. 71, 199-208 (2006). 
20. S. Kim, J.K. Lee, S.O. Kang, J. Ko, J.H. Yung, S. Fantacci, F. DeAngelis, M.D. DiCenco, K. Nazeeruddin, and M. Gratzel, "Molecular engineering of organic sensitizers for solar cell applications", J. Am. Chem. Soc. 128, 16701-16707 (2006).

21. T. Wu, M. Tsao, F. Chen, S. Su, C. Chang, H. Wang, Y. Lin, W. Yang, and I. Sun, "Synthesis and characterization of organic dyes containing various donors and acceptors", Inter. J. Mole. Sci. 11, 329-353 (2010).

22. M. Hosseinnezhad, A. Khosravi, K. Gharanjig, and S. Moradian, "The comparison of spectra and dyeing properties of new azonaphthalimide with analogues azobenzene dyes on natural and synthetic polymers", Arab. J. Chem., (2014), doi: 10.10161j.arabjc.2013.12.027.

23. R. Ashokkumar, A. Kathiravan, and P. Ramamurthy, "Aggregation behaviour and electron injection/recombination dynamics of symmetrical and unsymmetrical Zn-phthalocyanines on $\mathrm{TiO}_{2}$ film", Phys. Chem. Chem. Phys. 16, 1015-1021 (2014).

24. S. Park, Y. Won, Y. Choi, and J. Kim, "Molecular design of organic dyes with double electron acceptor for dye-sensitized solar cell", Energy Fuel. 23, 3732-3739 (2009).

25. S. Ananth, T. Arumanayagam, P. Vivek, and P. Murugakoothan, "Direct synthesis of natural dye mixed titanium di- oxide nano particles by sol-gel method for dye sensitized solar cell applications", Optik 125, 495-498 (2014).

26. M. Hosseinnezhad, S. Moradian, K. Gharanjig, and F. Afshar Taromi, "Synthesis and characterization of eight organic dyes for dye-sensitized solar cells", Mater. Technol. 29, 112-117 (2014).

27. M. Hosseinnezhad, K. Gharanjig, and S. Moradian, "Effect of anti-aggregation agent on photovoltaic performance of indoline sensitized solar cells", Mater. Technol. 30, 189-192 (2015).

28. Y. Ooyama, M. Kanda, K. Uenada, and J. Ohshita, "Effect of substituents in catechol dye sensitizers on photovoltaic performance of type II dye-sensitized solar cells", Chem. Phys. Chem. 16, 3049-3057 (2015).

29. J. Chang, C. Lee, D. Kumar, P. Chen, L. Lin, K.R. Thomas, and $\mathrm{K}$. Ho, "Co-sensitization promoted light harvesting for dye-sensitized solar cells using unsymmetrical squaraine dye and novel pyrenoimidazole-based dye", J. Power Sources. 240, 779-785(2013). 